\title{
ANALISIS KEGAGALAN KATUP BUANG PADA MESIN PEMBANGKIT LISTRIK TENAGA DIESEL (PLTD)
}

\author{
Ridwan Usman \\ Program Studi Teknik Industri, Universitas Indraprasta PGRI \\ Email: ridwansmn@gmail.com
}

\begin{abstract}
Abstrak
Analisis kegagalan katup buang (exhaustvalve) pada mesin Pembangkit Listrik Tenaga Diesel (PLTD) dipengaruhi oleh bahan bakar akibat proses pembakaran tidak sempurna, pembebanan termal, peningkatan panas berlebih (overheated) dan kelelahan material yang terjadi pada daerah permukaan piringan katup berupa retakan, patahan serta pengendapan deposite. Untuk melakukan analisis ini berdasarkan fakta yang ditemukan penyebab kerusakan beberapa pengujian dilakukan seperti komposisi kimia, fraktografi, metalografi, analisis kualitatif deposit patahan dengan SEM dan EDX. Analisis komposisi kimia unsur pada material dasar katup (valve) terbuat dari baja Martensitic. Paduan katup terdapat $\mathrm{Cr}-\mathrm{Si}$ sudah sesuai untuk material katup dengan fungsi unsur $\mathrm{Si}$ untuk menahan aus dan meningkatkan ketahanan korosi, sedangkan penambahan $\mathrm{Cr}$ untuk meningkatkan kekuatan pada temperatur tinggi dan ketahanan korosi. Adanya perbedaan kekerasan yang cukup signifikan antara lapisan dan material dasar katup.
\end{abstract}

Kata kunci : Katup buang,analisis pengujian material.

\section{Pendahuluan}

Energi listrik merupakan salah satu kebutuhan pokok yang sangat penting dalam kehidupan manusia saat ini, dimana hampir semua aktivitas manusia berhubungan dengan energi listrik. Banyak daerah-daerah terpencil di Indonesia yang belum mendapat pasokan energi listrik yang cukup untuk kebutuhan sehari-hari. Keterbatasan pasokan listrik ini disebabkan penggunaan listrik yang berlebih dalam kehidupan sehari-hari baik itu di rumah tangga, perusahaan maupun industri.

Untuk mengatasi keterbatasan pasokan listrik ini, maka banyak didirikan pembangkitpembangkit listrik di Indonesia. Salah satunya Pembangkit Listrik Tenaga Diesel (PLTD). PT X perusahaan yang bergerak di bidang Pembangkit Listrik Tenaga Diesel (PLTD), penyedia jasa ketenagalistrikan secara menyeluruh melalui Temporary Power, Operations Maintenance dan Power Optimization. Investasi Listrik Swasta (IPP) yaitu pembangkit listrik milik swasta yang memproduksi energi listrik.

Perusahaan ini dalam data laporannya telah terjadi kegagalan terutama pada katup buang (exhaust valve). Dari sampel yang di ambil terjadi patahan sekitar $90 \%$ pada katup buang dan mengalami diskolorasi akibat panas (heat discolorasi) di daerah piringan katup setelah pengoperasian pada suhu $416^{\circ} \mathrm{C}$ dan juga adanya pengendapan deposit pada katup hisap dan katup masuk.

Ada beberapa faktor penyebab terjadinya kegagalan seperti pembebanan termal, peningkatan panas berlebih (overheated) dan kelelahan material yang mengakibatkan patahan, retakan serta pengendapan deposit akibat panas yang tinggi di daerah lapisan piringan katup buang. Kondisi mesin yang panas tinggi (overheated), disebabkan oleh sistem pendingin yang tidak bekerja dengan baik karena tersumbatnya aliran pendingin dan sistem pelumasan kadar serta viskositas oli mengalami penurunan sehingga sering dilakukan penambahan oli. Selain itu desain katup yang tidak sesuai standar seperti pemilihan material terutama komposisi kimia menjadi salah satu faktor penyebab kegagalan katup sehingga tidak tahan terhadap temperatur tinggi serta proses pembuatan/produksi seperti proses pengelasan atau perlakuan panas yang salah (Yildiz, 2010). 
Kegagalan yang terjadi pada komponen katup pembakaran dalam (Internal Combustion) berdampak pada suara mesin menjadi kasar, bergetarnya mesin tidak normal dan kehilangan tenaga (power). Breakdown maintenance akibat penggantian katup dapat merugikan perusahaan karena berhentinya proses produksi (Enwikipedia,2014; Yildiz, 2010).

Penelitian tentang Failure Analysis Valve telah banyak dilakukan. Hasil penelitian Larry Carley (2005) menunjukkan bahwa dalam kondisi beban penuh, katup buang (exhaust valve) dapat mencapai suhu $800^{\circ} \mathrm{C}$ sampai titik merah. Katup dengan diameter besar, suhunya lebih panas dari pada yang lebih kecil, dan suhu pada katup meningkat sesuai dengan putaran mesin. Peningkatan rasio kompresi sebagai suatu proses untuk menurunkan suhu katup, tetapi jika kompresi dilakukan terlalu tinggi dalam proses pembakaran. Efek sebaliknya biasanya diasumsikan bahwa suhu katup buang (exhaust valve) yang terlalu tinggi dan telatnya pembakaran bisa berakibat katup buang terlalu panas. Kondisi ini mempengaruhi proses pengapian dan campuran tidak sempurna, tetapi sejumlah besar experimen dilakukan pada mesin tertentu menunjukkan bahwa berlaku sebaliknya, suhu katup buang (exhaust valve) yang lebih rendah dengan campuran tidak sempurna dan pengapian yang lambat.

Berdasarkan pemaparan di atas, perlu dilakukan penelitian lanjut untuk mencari dan menentukan akar penyebab kegagalan yaitu patahan di daerah lapisan permukaan katup buang berdasarkan teori kegagalan. Sehingga dapat merumuskan langkah-langkah penanggulangan untuk mencegah terjadinya kerusakan yang sejenis. Analisis kegagalan (failure analysis) dilakukan dengan pengujian sifat mekanik material seperti pengujian metalografi, fraktrografi, uji kekerasan, komposisi (spectrometry) dan SEM-EDX. Hasil dari penelitian ini diharapkan dapat memberikan rekomendasi untuk mengurangi tingkat kegagalan pada katup masuk dan katup buang (inlet and exhaust valve).

\section{Tinjauan Pustaka}

Motor diesel merupakan motor pembakaran dalam (Internal Combustion Engine), dimana bahan bakarnya di semprotkan kedalam silinder pada waktu torak hampir mencapai titik mati atas (TMA). Oleh karena udara didalam silinder mempunyai temperatur yang tinggi, maka bahan bakar akan terbakar sendirinya. Motor diesel umumnya mempunyai beberapa kontruksi utama di antaranya adalah torak, batang torak, poros engkol, katup, pompa bahan bakar bertekanan tinggi dan mekanisme penggerak lainnya.

Daya yang dihasilkan motor diesel diperoleh melalui pembakaran bahan bakar yang terjadi di dalam silinder. Hal ini menyebabkan gerakan translasi torak di dalam silinder yang dihubungkan dengan poros engkol pada bantalannya melalui batang penghubung (Connecting Rod)(G. Nofica, 2012).

Katup atau engine valve merupakan komponen penting dalam sebuah kendaraan. Engine valve berada pada kepala silinder pada setiap kendaraan yang berbentuk seperti payung. Engine valve terbagi menjadi dua kerja. Pertama katup hisap (inlet valve) berfungsi untuk membuka saluran bahan bakar yang akan masuk pada ruang bakar, katup hisap ini bekerja atau membuka pada saat piston akhir langkah buang sampai pada saat piston awal langkah kompresi. Kedua katup buang (exhaust valve) berfungsi untuk membuka saluran buang yang akan membuang sisa-sisa pembakaran, katup buang ini bekerja atau membuka pada saat piston akhir langkah kerja sampai pada saat piston awal langkah hisap (Hetharia, 2012).

Mekanisme katup adalah suatu mekanisme pengaturan proses pembukaan dan penutupan katup pada saluran masuk dan buang motor bakar. Mekanisme tersebut berfungsi untuk membuka dan menutup katup hisap dan katup buang (inlet \& exhaustvalve) yang sesuai dengan firing order suatu silinder dan proses pengerjaannya, yang memasukkan campuran bahan bakardan udara serta mengeluarkan gas buang sisa pembakaran. Pada kendaraan mobil dijumpai kerusakan pada sistem yang menyebabkan timing belt pada kendaraan ini 
putus, sehingga menyebabkan, pengguna mobil harus mengganti engine valve akibat katup tersebut bengkok dan tidak dapat dipakai lagi.

Kepala katup atau sering disebut daun katup untuk katup hisap (inlet valve), diameternya lebih besar dibandingkan dengan daun katup buang. Hal ini dimaksudkan agar pemasukan gas bersih dapat lebih sempurna. Temperatur rata-rata yang terjadi pada daun katup hisap sekitar $250^{\circ} \mathrm{C}$ sampai dengan $275^{\circ} \mathrm{C}$ sedangkan pada katup buang (exhaust valve) sekitar $700^{\circ} \mathrm{C}$ sampai dengan $760^{\circ} \mathrm{C}$. Perbedaan ini disebabkan pada katup hisap (inlet valve) hanya di lewati gas bersih yang dingin sehingga temperaturnya lebih rendah di banding katup buang, sedangkan katup buang (exhaust valve) terus menerus di lewati oleh gas bekas pembakaran yang panas. Dengan temperatur seperti tersebut diatas, katup tidak boleh berpijar, karena akan menyebabkan timbulnya pre-ignition atau knoking. Agar dapat memenuhi ketentuan diatas, maka bahan katup buang (exhaust valve) harus dibuat lebih kuat dari bahan katup hisap (inlet valve). Selain itu juga diameter katup masuk (inlet valve) dibuat lebih besar agar pemasukan gas bersih dapat lebih sempurna. Disamping itu juga bahan katup harus mempunyai angka pemuaian yang kecil agar kerja mesin dapat sempurna, katup buang yang lebih kecil ini juga disesuaikan hasil pembakaran dari perpindahan panas ke kepala silinder. Pada mesin dengan tekanan kompresi tinggi, temperatur daun katup akan tinggi sekali, untuk itu pada mesin tersebut biasanya di lengkapi dengan katup yang mempunyai bahan pendingin (B Dinesh Prabu, 2013).

Jenis operasi mekanisme katup terdiri dari pegas katup, paduan batang dorong, lengan rocker, tappets, diagram katup timing, didesain untuk mengetahui proses campuran udara dan bahan bakar di dalam mesin silinder dan memaksa membuang keluar sisa pembakaran pada waktu yang tepat, beberapa sistem kontrol diperlukan untuk mengatur katup (B Dinesh Prabu, 2013).

Kontruksi katup terdiri dari kepala katup (valve head) dan batang katup (valve stem). Katup ini bentuknya mirip dengan jamur. Pada kepala katup bentuknya disesuaikan dengan kebutuhannya agar gas yang keluar masuk dapat mengalir dengan lancar. Disamping itu juga pada kepala katup terdapat suatu permukaan yang nantinya akan berhimpit dengan dudukan katup. Bagian katup yang berhimpitan ini disebut permukaan katup (valve face). Permukaan katup ini dibuat miring yang sesuai dengan kemiringan pada permukaan dudukan katup.

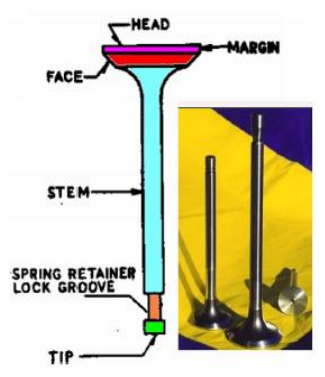

\section{Gambar 1. Bagian-Bagian Komponen Katup}

Untuk menemukan penyebab akar masalah dari analisis kegagalan harus menggunakan langkah-langkah implementasi analisis kegagalan, berpikir secara logis dengan fakta dan mengikuti tanda-tanda yang mengarah pada akar penyebab kegagalan. Langkah-langkah mengikuti pemecahan masalah logis, misalkan permasalahan tentang pengaturan bahan bakar yang tinggi penyebab kegagalan valve, kesalahan bahan bakar, hambatan udara masuk, exhaust, masalah sistem pendingin, masalah bahan bakar atau timing valve, atau penyetelan valve terlalu ketat. Ketika valve patah, valve bagian bawah sering kali rusak secara fisik oleh piston dan cylinder head. Petunjuk pada komponen yang hilang dan analisis sering kali 
terbatas pada stem akhir dari valve semacam itu dan bukti tidak langsung lainnya (Hetharia, 2012).

\section{Metodologi Penelitian}

Analisis data pada pengujian ini terdiri dari dua tahap yaitu tahap pengumpulan data dan tahap pengolahan data. Sampel di ambil dari kegagalan katup yang mengalami pembebanan termal karena suhu tinggi dan tekanan di dalam silinder nomor 3 (tiga) yang mengalami patahan akibat panas berlebih (overheated) didaerah lapisan piringan katup dan juga adanya pengendapan (deposit) baik pada katup buang (exhaust valve) ataupun katup masuk (inlet valve).

Pengumpulan data meliputi kegiatan pengambilan data sampel terhadap 2 (dua) komponen katup buang (exhaust valve) yaitu komponen katup rusak dan tidak rusak sebagai pembanding. Untuk tahap berikutnya menganalisis dan mengidentifikasi faktor-faktor apa saja yang mempengaruhi kegagalan komponen katup.

Gambar sampel di ambil dari kegagalan katup yang mengalami pembebanan termal karena suhu tinggi dan tekanan di dalam silinder. Kondisi kegagalan karena suhu yang tinggi pada sifat mekanik bahan dan korosi terlihat berupa patahan (cowak) pada lapisan katup buang serta adannya pengendapan (deposit) pada katup buang (exhaust valve) .

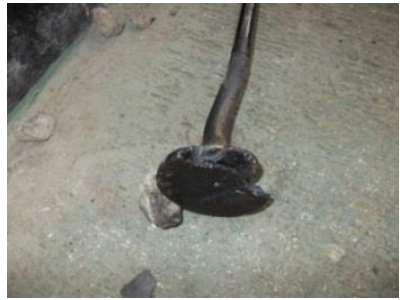

(a)

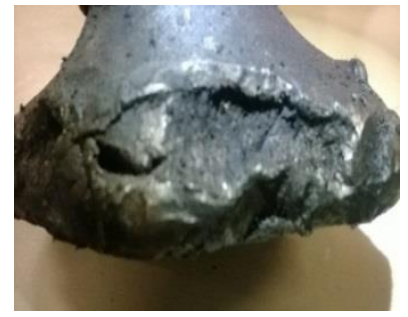

(b)

Gambar 2. Sampel (a) Katup Buang (exhaust valve) Mengalami Rompal (Cowak) dan (b) Katup Buang Mengalami Patah dan Pengendapan (Deposit)

Pada penelitian ini menggunakan beberapa tahap analisis yaitu Metalografi, Fraktrografi, komposisi kimiadan SEM-EDX.

\section{Metalografi}

Analisis metalografi dibedakan menjadi 2 (dua) jenis, yaitu: Pengamatan Struktur Makro dan Pengamatan Struktur Mikro. Tujuan analisis struktur makro untuk mengetahui adanya permasalahan cacat (segregasi) dari unsur-unsur Fosfor (P), Sulfur (S) dan lain-lain. Adanya inklusi, rongga udara, rongga penyusutan dan lain sebagainya. Analisis struktur mikro dilakukan dengan menggunakan Normal Mikroskop dengan pembesaran lebih dari $20: 1$ (20x). Tujuan dari analisis struktur mikro antara lain :1) Mengetahui sifat-sifat logam dan paduanya berdasarkan bentuk gambar struktur mikronya.; 2) Mengetahui bentuk struktur material logam yang telah atau belum mengalami proses pengerjaan/perlakuan panas (seperti treatment, quenching, normalization, hardening dan sebagainya), pengerjaan dingin, proses pengelasan dan lain-lain; dan 3)Mengetahui sebab-sebab terjadinya penyimpangan struktur bahan logam atau jenis cacat yang lain (retakan, korosi dan lain sebagainya) (ASM Metal Handbook. 2004).

\section{Fraktrografi}

Fraktrografi adalah suatu disiplin ilmu pengetahuan yang mempelajari serta menganalisis karakteristik struktur patahan atau retakan logam. Pada dasarnya suatu analisis patahan atau retakan bertujuan untuk mengetahui penyebab kegagalan dalam suatu material. Kegagalan 
pada material tersebut dapat diaplikasikan atas penyebab kerusakan, sebagai berikut (Yuvraj K lavhale ,2014):

1. Material itu sendiri. Untuk material suatu beban yang diterima suatu komponen tidak sesuai dengan spesifikasinya yang meliputi : komposisi kimia, kekuatan mekanik dan dimensi.

2. Pengaruh proses pembuatan. Akibat kesalahan proses pengerjaan ini akan memberikan efek terhadap kerusakan material/komponen tersebut, meliputi : Perlakuan panas, pengelasan, pengecoran pengeboran dan lain-lain.

3. Desain. Kesalahan desain dapat menyebabkan terjadinya kerusakan akibat adanya kosentrasi tegangan pada suatu titik.

4. Operasional. Besar beban dan jenis yang diterima oleh komponen yang bersangkutan akan sangat besar pengaruhnya pada kerusakan komponen tersebut. Oleh karena itu adanya beban statis yang berlebihan (over loading) atau adanya beban dinamis logam akan mengalami patah lelah (T Becker William and J. Shipley Roch,2002)

\section{Pengujian Komposisi Kimia}

Pengujian komposisi ini dilakukan untuk mengetahui komposisi kimia yang terkandung di dalam Baja Karbon dan Baja tahan karat. Analisis komposisi kimia dilakukan untuk mengetahui jenis material yang digunakan pada material katup, sehingga kegagalan yang berawal dari kesalahan penggunaan material dapat diketahui. Sampel diambil dari material dasar piringan katup buang, Sampel dipotong dengan mesin pemotong untuk mendapatkan ukuran 10 x $10 \mathrm{~mm}$. Permukaan sampel kemudian diamplas kasar untuk membuang kotoran yang ada dipermukaan material dasar katup. Kemudian lapisan katup dilakukan analisis secara kualitatif dengan alat komposisi (spectrometry) (Caesarvery,2012).

\section{Hasil dan Pembahasan}

Material dasar katup buang (exhaust valve) harus memiliki sifat tahan temperatur tinggi, memiliki koefisiensi ekspansi panas yang tinggi dan bersifat panas yang tinggi, tahan aus,ketahanan terhadap kejut panas, ketahanan korosi tinggi dan bersifat ringan. Selain itu adanya kenaikan dan penurunan temperatur pada katup dari data DAR (Data Analisis Record) pada temperatur $416{ }^{\circ} \mathrm{C}$ material katup buang (exhaust valve) mengalami kerusakan patahan dan deposit. Sedangkan deposit yang terbentuk pada katup buang berasal dari reaksi bahan bakar dan oli sebagai lubrikasi selama pembakaran Sulfur Dioksida, Sulfur Trioksida, Sodium Oksida dan Panadium Pentaoksida. Pada temperatur $550{ }^{\circ} \mathrm{C}$ garam-garam deposit akan mencair sebagai akibat korosi pada katup buang (exhaust valve) (ASM Metal Handbook, 2004).

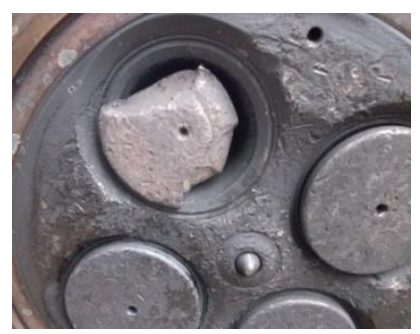

Gambar 3. Permukaan Blok Mesin PLTD dan Katup Buang (Exhaust Valve) Mengalami Patah dan Rompal Serta Terjadi Penumpukkan Karbon Sisa Bahan Bakar

Gambar sampel di ambil dari kegagalan katup yang mengalami pembebanan termal karena suhu tinggi dan tekanan di dalam silinder. Kondisi kegagalan karena suhu yang tinggi pada sifat mekanik bahan dan korosi terlihat berupa patahan (cowak) pada lapisan katup buang 
serta adanya pengendapan (deposite) permukaan katup buang (exhaust valve) atau katup hisap (inlet valve).

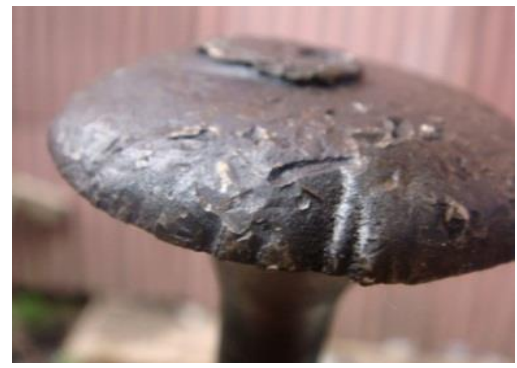

(a)

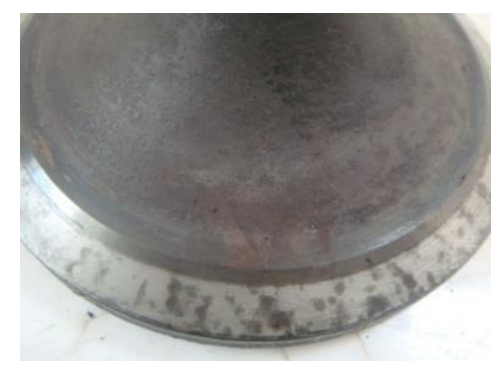

(b)

Gambar 4. (a) Katup buang (exhaust valve) permukaan katup rompal (cowak) dan patah serta pengendapan deposite. (b) Sampel katup hisap (inlet valve) pada permukaan katup mengalami retak dan deposite

\section{Makro visual}

Untuk mengetahui adanya permasalahan cacat (segregasi) dari unsur-unsur Fosfor ( $\mathrm{P})$, Sulfur (S) dan lain-lain, Serta adanya inklusi, rongga udara, rongga penyusutan dan lainnya. Makro visual di lakukan pada permukaan patahan pada piringan katup buang (exhaust valve) seperti ditunjukkan pada Gambar 5 dibawah ini.
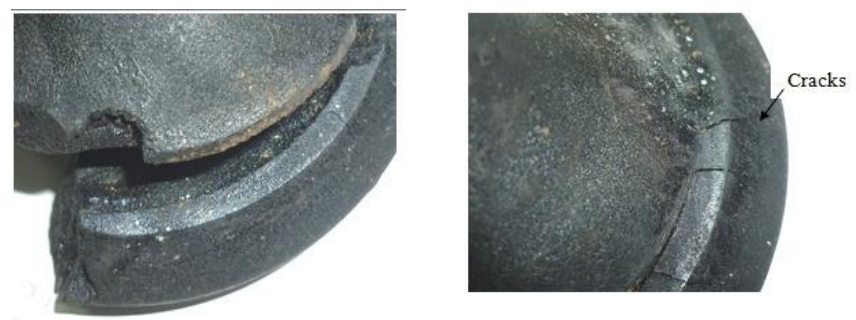

\section{Gambar 5. Photo Makro (Exhaust Valve) Sampel Katup Kondisi Patah dan Photo Makro Retak}

Separuh dari kepala katup (valve) lepas dan bidang yang pecah menghantam/menahan pergerakan kerja katup (valve) yang berakibat batang katup bengkok. Pada Gambar 5. photo makro katup (valve) yang patah berawal antara bidang singgung dengan casing blok mesin. Bentuk retak menjalar melingkar pada derah yang dikeraskan. Pengambilan sampel metalografi di 3 lokasi yaitu pada batang dan dikepala katup (valve). Selama katup menutup kombinasi aus dan tumbukan (impact) akan mengarah pada terjadinya keausan dibagian dudukan katup dan piringan katup. Adanya tumbukkan saat katup menutup mengakibatkan deformasi plastis pada permukaan dudukan (seat) dan membentuk serangkaian tonjolan dan cekungan. Gambar 6. photo makro retak memperlihatkan menjalar antara daerah yang dikeraskan dengan materail dasar (HAZ). Hal ini akan mengarah pada terjadinya permukaan patahan ditemukan adanya bentuk patah lelah.

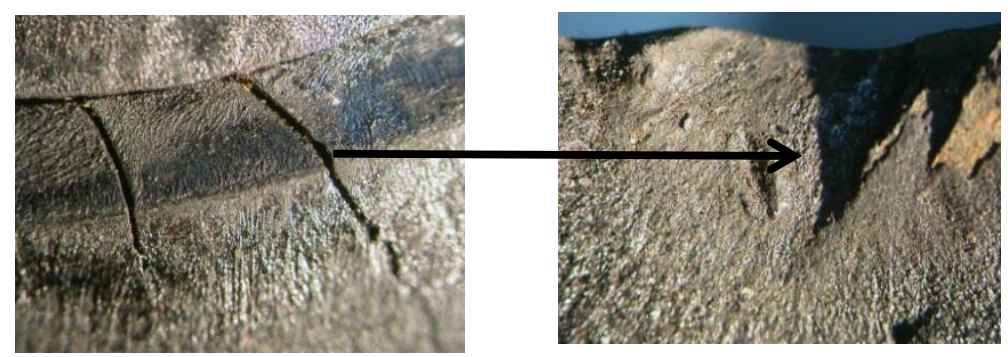

Gambar 6. Photo Makro Retak 


\section{Mikro Visual}

Analisis struktur mikro pada katup buang (exhaust valve). Analisis diawali dari struktur material mengalami proses pengerjaan/perlakuan panas (seperti trerment, quenching, normalization, hardening).

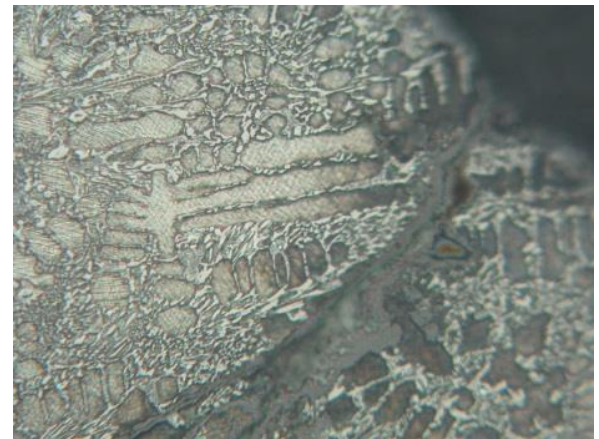

Gambar 7. Struktur Mikro Perbesaran dari Gambar 6 Berupa Dendrit-Austenit, pada Retakan Terlihat adanya Produk Korosi dari Bahan Bakar sebagai Bentuk Serangan Korosi Temperatur Tinggi

Pemeriksaan dengan analisis mikro mengungkapkan permukaan patahan halus dengan beach mark dan rachet mark. Patahan bending fatigue berasal dari atas, permukaan beban tensile pada katup. Gambar 8. patah antara material dasar (HAZ) dengan material penambah terkena temperatur tinggi sehingga melemahkan besi dan menyebabkan kepala katup (valve) melengkung.

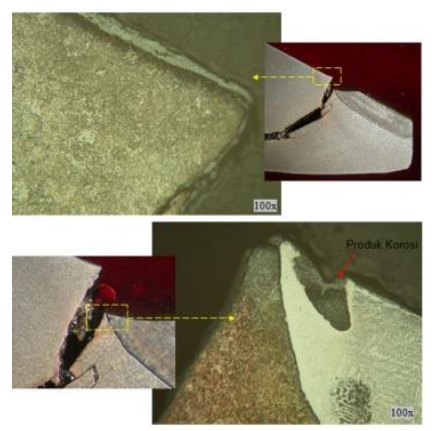

\section{Gambar 8. Perbesaran Gambar 6 Struktur Mikro pada Daerah Patah Antara Material Dasar/HAZ dengan Material Penambah (las) (Pada Daerah Las terdapat Produk Korosi yang Menunjukkan Adanya Serangan Korosi Temperatur Tinggi)}

\section{Fraktrografi}

Dari hasil pengujian SEM dan EDX terlihat bahwa katup buang (exhaust valve) telah mengalami perlakuan panas yakni akibat adanya kenaikan temperatur di dalam silinder nomor 3. Analisis SEM dan komposisi kimia atau EDX menunjukkan telah terjadi proses oksidasi pada permukaan material katup buang. Dari gambar 5. terlihat adanya pembentukan struktur iron-oxide yakni terbentuknya morfologi seperti lepidocrocite $(\gamma-\mathrm{FeOOH})$, yakni pengaruh temperatur pada tingkatan korosi dari baja AISI 304 dan stainless steel AISI 444 dengan minyak mentah pada baja karbon). Hal ini merupakan bagian dari permulaan korosi (intial corrosion), dan apabila kondisi ini terus berlanjut kemungkinan besar akan terbentuk produk korosi baru seperti magnetite $\left(\mathrm{Fe}_{3} \mathrm{O}_{4}\right)$ dan menyerang batas butir dari logam (materialcerdas,2009). 


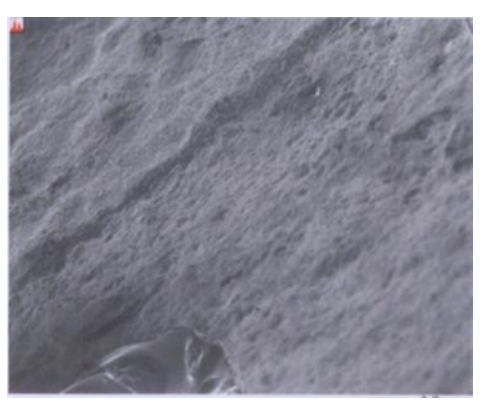

(a)

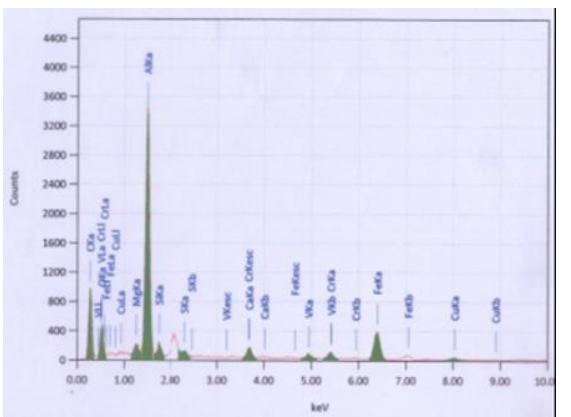

(b)

Gambar 9. (a) Fraktograsi Hasil SEM yang Mengalami Diskolorasi dan Terjadi Deposite yang Menempel pada Bagian Katup Buang (Exhaust Valve)

(b) Hasil Grafik Menunjukkan Terjadinya Peningkatan Karbon dan Terjadi Deposit yang Menempel

\section{Pengujian Komposisi Kimia}

Komposisi kimia material dasar katup buang (exhaust valve) harus memiliki sifat tahan temperatur tinggi, memiliki koefisien ekspansi panas yang tinggi, tahan aus, ketahanan terhadap kejut panas, ketahanan korosi tinggi dan bersifat ringan. Material dasar katup buang (exhaust valve), yang umum digunakan adalah baja tahan karat austenitik dengan penambahan nitrogen $(21-2 \mathrm{~N}, 21-4 \mathrm{~N})$, baja martensitik dengan paduan dasar $\mathrm{Cr}$ atau $\mathrm{Si}$ dan baja cor austenitik dengan ketahanan cor dan permesinan yang baik.

Tabel 1. Perbandingan Komposisi Kimia Standar AISI 504 dan Sampel Material Dasar Katup Buang.

\begin{tabular}{|c|c|c|c|}
\hline No & Unsur & $\begin{array}{c}\text { Kandungan Unaur } \\
\text { Hasil Pengujian B2TKS (\%wt) }\end{array}$ & $\begin{array}{c}\text { Standar AISI 504 } \\
(\% \mathrm{wt})\end{array}$ \\
\hline 1 & $\mathrm{C}$ & 0,323 & Max. 0,15 \\
\hline 2 & $\mathrm{Si}$ & 4,053 & Max. 1,0 \\
\hline 3 & $\mathrm{Mn}$ & 0,266 & Max. 1,0 \\
\hline 4 & $\mathrm{P}$ & 0,015 & Max. 0,04 \\
\hline 5 & $\mathrm{~S}$ & 0,028 & Max. 0,04 \\
\hline 6 & $\mathrm{Cu}$ & 0,057 & - \\
\hline 7 & $\mathrm{Al}$ & 0,019 & - \\
\hline 8 & $\mathrm{Cr}$ & 8,517 & $8.00-10.00$ \\
\hline 9 & $\mathrm{Mo}$ & 0,042 & $8.00-10.00$ \\
\hline 10 & $\mathrm{Ni}$ & 0,125 & - \\
\hline 11 & $\mathrm{~V}$ & 0,012 & - \\
\hline 12 & $\mathrm{Ti}$ & 0,011 & - \\
\hline 13 & $\mathrm{Nb}$ & 0,005 & - \\
\hline 14 & $\mathrm{Co}$ & $<0,002$ & - \\
\hline 15 & $\mathrm{~W}$ & $<0,002$ & \\
\hline
\end{tabular}

Dari analisis komposisi kimia di Tabel 1. diatas terdapat perbedaan antara kandungan hasil material yang diuji dan standar AISI 504 Nilai Karbon(C)hasil uji $=0,323 \%$; sedangkan standar $\mathrm{C}=\max 0,15 \%$.Kadar $\mathrm{C}$ melebihi standar berpengaruh terhadap ketahanan austenitik. Adapun penyebab kandungan Karbon berlebih padabahan katup buang (exhaust valve) akan bersifat rapuh, tidak tahan terhadap temperatur berlebih. Sehingga pengaruh korosi dari dampak bahan bakar sebagai bentuk pengaruh temperatur tinggi. 
Berikutnya kadar Silikon $(\mathrm{Si})$ hasil uji $=4,053 \%$; sedangkan standar $=\max 1,0 \%$. Kelebihan silikon mempunyai sifat elastis/keuletannya tinggi tetapi juga menambah kekerasan dan ketajaman pada baja. Dan Mangan (Mn) hasil uji =0,266; sedangkan standar Mn $=\max 1,0$ $\%$. Kurang dari standar, hal ini akan berpengaruh terhadap sifat yang tahan terhadap gesekan dan tahan tekanan (impact load) (Yuvraj K lavhale, 2014).

\section{Simpulan dan Saran}

\section{Simpulan}

Berdasarkan hasil penelitian dapat diambil kesimpulan sebagai berikut :

1. Kerusakan pada piringan katup buang (exhaust valve) karena adanya lapisan oksida ataukotoran (oxide debris) yang diakibatkan hasildari bahan bakar atau sisa pembakaran yang tidak sempurna, dipicu oleh peningkatan temperatur saat proses pembakaran yang akan menghasilkan partikel-partikel oksida yang halus dan keras (oxide glazes).

2. Efek dari panas yang tinggi diakibatkan oleh sistem pembakaran (komposisi bahan bakar dan udara) sistem pelumasan, sistem pendingin tidak bekerja secara maksimal

3. Dari analisis Scanning Electron Microscopy (SEM) menunjukan bahwa material batang torak mengalami diskolorasi karena panas, karakteristik lapisan kerak yang terbentuk halus dan mudah untuk dibersihkan.

\section{Saran}

Untuk menghindari terjadinya kerusakan yang sejenis pada katup buang (exhaust valve) maka disarankan sebagai berikut :

1. Untuk perusahaan yang bergerak dalam bidang pemeliharaan (maintenance), diperlukan upaya peningkatan pemahaman terhadap manajemen pemeliharaan khususnya pada pembacaan tren parameter data sebagai bagian dari proses kontrol kemampuan mesin (condition monotoring). Lebih dari itu langkah korektif juga perlu dilakukan yang berkaitan dengan penelitian ini yakin meningkatkan skill teknisi dalam melakukan penyetelan atau pengencangan baut sesuai dengan prosedur yang dikeluarkan oleh produsen mesin diesel $9 \mathrm{~L}$ 21/31.

2. Perlu dipertimbangkan kemampuan dan kehandalan daya tahan mesin sehingga bisa ditentukan kemampuan jam operasional mesin tersebut.

3. Perlu dilakukan penelitian lanjutan mengenai kerusakan pada silinder liner, injektor sistem pendinginan dan turbocharger.

4. Data hasil pengujian menjadi acuan, sebagai konsumen untuk mengetahui keuntungan dan kelemahan mesin diesel $9 \mathrm{~L} \mathrm{21/31}$. Produsen (pembuat produk) mengetahui kelemahan dari mesin yang mereka buat, terutama katup buang (exhaust valve) sebagai langkah perbaikan.

\section{Daftar Pustaka}

ASM Metal Handbook. (2004). Metallography and Microstructure, ASM International Handbook Committee :Volume 9. 1985. Ohio

Caesarvery, (2012). Pengujian Komposisi Spectrometry. Diakses dari www.google.com/ blogspot.com/gc-ms-html.

Enwikipedia.(2014). Diesel Generator. Diakses dari www.google.com/wiki.html.

G. Nofica. (2012). Teori Dasar Mesin Diesel. Diakses dari www.google.com/ Eprints.undip.ac.id

Larry Carley. (2005).Valve Selection Hot Valve Material for Hot Engine. Diakses dari www.google.com/enginebuildermag.html 
Hetharia, M. (2012). Analisa Pengaruh Kapasitas Udara untuk Campuran Bahan Bakar Terhadap Prestasi Mesin Diesel. ARIKA, Vol.06, No.1 ISSN : 1978 - 1105.

Materialcerdas.(2009). Teori-dasar-scanning-electron-microscopy. Diakses dari www.google. com/ wordpress.com /https://materialcerdas

T Becker William and J. Shipley Roch.(2002). Failure Analysis and Prevention. ASM Handbook Committee.Volume 10.

Yildiz, (2010). Investigation of exhaust valve failure in heavy - duty diesel engine. Guzi University Journal of Science GUJ Sci. 23 (4): 493-499.

Yuvraj K lavhale. (2014). Overview of Failure Trend of Inlet \& Exhaust Valve. IJMET Volume 5, Issue 3, March,pp.104-113. 